\title{
Prevalence of multidrug-resistant enterococci in a tertiary care hospital in Mumbai, India
}

\author{
Vaibhav R Deshpande, Mohan G Karmarkar, Preeti R Mehta \\ Department of Microbiology, Seth GS Medical College and KEM Hospital, Parel, Mumbai, 400 012, Maharashtra, \\ India
}

Key words: Enterococcus; multidrug-resistance; VRE; high-level resistance

J Infect Dev Ctries 2013; 7(2):155-158.

(Received 15 September 2012 - Accepted 19 November 2012)

Copyright $(C 2013$ Deshpande et al. This is an open-access article distributed under the Creative Commons Attribution License, which permits unrestricted use, distribution, and reproduction in any medium, provided the original work is properly cited.

\section{Introduction}

Enterococci are one of the major causes of nosocomial and community-acquired infections. In recent years, the evolution of antimicrobial resistance in enterococci has posed enormous challenges for clinicians. The antimicrobial therapy of enterococcal infections is complicated because of the inherent resistance shown by enterococci to several commonly used antibiotics such as cephalosporins, low-level aminoglycosides, and low-level clindamycin and perhaps more importantly, because of their acquired resistance to all currently available antibiotics, that leaves limited medicative options and results in the selection and spreading of multidrug-resistant (MDR) strains in hospitals [1,2]. Empirical use of antibiotics, absence of national guidelines for screening patients for MDR bacteria and lack of sufficient information and programs to control rapid spread of enterococci has led to increased mortality caused by enterococcal infections [3-5]. Knowledge of the antibiogram is essential to formulate therapeutic strategies for treating enterococcal infections [1]. This prospective study aimed to investigate species prevalence and extent of antimicrobial resistance among clinical isolates of enterococci in a tertiary care hospital in India.

\section{The study}

Clinical isolates of enterococci from KEM Hospital, Mumbai, India, were studied at the Department of Microbiology. Enterococci were identified to the species level by standard biochemical tests [6]. Species confirmation was accomplished by the use of species-specific PCR assays [7]. Antibiograms were performed by the breakpoint broth microdilution method as standardised by the Clinical and Laboratory Standards Institute (CLSI) $[8,9]$. The antibiotics tested were ampicillin, penicillin, highlevel gentamicin (HLG), high-level streptomycin (HLS), vancomycin, teicoplanin, erythromycin, tetracycline, ciprofloxacin, nitrofurantoin, rifampin, chloramphenicol, and linezolid. Minimum inhibitory concentrations (MICs) of the most clinically significant antibiotics (ampicillin, penicillin, gentamicin, streptomycin, vancomycin, teicoplanin, and linezolid) were determined by the broth microdilution method in accordance with the CLSI guidelines [2,8]. E. faecalis ATCC 29212 and E. faecalis ATCC 51299 were used for quality control. Statistical analysis was performed employing Fisher's exact test $(\mathrm{p}<0.05)$.

In this study, $291 \quad(11.6 \%)$ enterococci were isolated from 2,500 clinical specimens. Enterococcus faecalis $(70.1 \%$; 204/291) was the predominant species identified, followed by Enterococcus faecium (29.9\%; 87/291). Predominance of E. faecalis in the endogenous flora of the body could be the reason behind its high proportion among the hospital isolates.

Since beta-lactams remain the drug of choice for most enterococcal infections, increasing resistance to these antibiotics is of concern. The rate of resistance to ampicillin (64.9\%) and penicillin (75.9\%) among isolates in this study was higher than the resistance rates reported recently from India (Table 1) $[4,10,11]$. High-level resistance to ampicillin (MIC $\geq 64 \mu \mathrm{g} / \mathrm{ml}$ ) and penicillin (HLPR) (MIC $\geq 128 \mu \mathrm{g} / \mathrm{ml}$ ) was observed in $28.9 \%$ (84/291) and $34.0 \%$ (99/291) of the isolates, respectively, with MICs raised up to 512 $\mu \mathrm{g} / \mathrm{ml}$ (Table 2) [9]. The rate of HLPR reported in this 
Table 1. Antimicrobial resistance rates of enterococcal isolates of the study

\begin{tabular}{|c|c|c|c|}
\hline \multirow[t]{2}{*}{ Antibiotic } & \multicolumn{3}{|c|}{ Resistance $^{\#}$} \\
\hline & $\begin{array}{c}\text { E. faecalis } \\
(\mathbf{n}=\mathbf{2 0 4}) \\
\text { n }(\%)\end{array}$ & $\begin{array}{c}\text { E. faecium } \\
(\mathbf{n}=\mathbf{8 7}) \\
\text { n }(\%)\end{array}$ & $\begin{array}{c}\text { Total } \\
(\mathrm{n}=\mathbf{2 9 1}) \\
\mathbf{n}(\%)\end{array}$ \\
\hline Ampicillin & $125(61.3)$ & $64(73.6)$ & 189 (64.9) \\
\hline Penicillin G & $148(72.5)$ & $73(83.9)$ & $221(75.9)$ \\
\hline HLG & $147(72.1)$ & $67(77.0)$ & $214(73.5)$ \\
\hline HLS & $132(64.7)$ & $74(85.1)$ & $206(70.8)$ \\
\hline Vancomycin ${ }^{\mathrm{a}}$ & $38(18.6)$ & $19(21.8)$ & $57(19.6)$ \\
\hline Teicoplanin ${ }^{\mathrm{b}}$ & $9(4.4)$ & $24(27.6)$ & $33(11.3)$ \\
\hline Erythromycin ${ }^{\mathrm{c}}$ & $184(90.2)$ & $84(96.5)$ & $268(92.1)$ \\
\hline Tetracycline $^{\mathrm{d}}$ & $165(80.9)$ & $81(93.1)$ & $246(84.5)$ \\
\hline Ciprofloxacin & $194(95.1)$ & $84(96.5)$ & $278(95.5)$ \\
\hline Nitrofurantoin & $153(75.0)$ & 79 (90.8) & $232(79.7)$ \\
\hline Rifampin & $65(31.9)$ & $59(67.8)$ & $124(42.6)$ \\
\hline Chloramphenicol $^{\mathrm{f}}$ & $81(39.7)$ & $42(48.3)$ & $123(42.3)$ \\
\hline Linezolid $^{\mathrm{g}}$ & $1(0.5)$ & $6(6.9)$ & $7(2.4)$ \\
\hline
\end{tabular}

study was slightly lower than that reported in the literature $[4,12]$. This finding could be due to the limited use of penicillin in the management of infections in our hospital. To the best of our knowledge, this is the first report on high-level ampicillin resistant enterococci from India.

High-level resistance to aminoglycosides (HLAR) is of great clinical concern, since it eliminates synergy with cell wall active antibiotics, which renders treatment of serious enterococcal infections difficult [1]. In the present study, a high proportion of tested isolates exhibited resistance to HLG $(73.5 \%)$ and HLS (70.8\%), with MICs raised up to $4000 \mu \mathrm{g} / \mathrm{ml}$ and 8000 $\mu \mathrm{g} / \mathrm{ml}$, respectively (Tables 1 and 2). Combined resistance to HLG and HLS was found in 58.8\% $(171 / 291)$ of all isolates, indicating the total elimination of synergy between aminoglycosides and cell-wall active agents. Compared to previous reports, this study has found a higher incidence of HLAR especially HLSR [10-13]. This result could be attributed to the increased use of streptomycin in our hospital setting alternatively to gentamicin for the treatment of HLGR enterococci infections [14].

With increasing resistance to high-level aminoglycosides and penicillins, glycopeptides can provide a valuable treatment option [2]. Glycopeptideresistant enterococcal (VRE) infections can be fatal. In the present study, vancomycin resistance was detected in $19.6 \%$ of the isolates and high-level vancomycin resistance (MIC $\geq 64 \mu \mathrm{g} / \mathrm{ml}$ ) was exhibited by $15.5 \%$ $(45 / 291)$ of the isolates with MICs raised up to 2048 $\mu \mathrm{g} / \mathrm{ml}$ (Tables 1 and 2) [9]. All (11.3\%) teicoplaninresistant isolates showed high-level resistance to teicoplanin (MIC $\geq 16 \mu \mathrm{g} / \mathrm{ml}$ ) with MICs raised up to $256 \mu \mathrm{g} / \mathrm{ml}$ (Tables 1 and 2) [1]. The frequency and extent of glycopeptide resistance in this study were much higher compared to those of previous reports from India [4,10-12]. Although vancomycin resistance is low in India compared to that in western countries, its rising rate is concerning [13].

Treatment of infections caused by VRE is extremely problematic because of the 
Table 2. MIC ranges, $\mathrm{MIC}_{50 \mathrm{~s}}$, $\mathrm{MIC}_{90 \mathrm{~s}}$, and high-level resistance (HLR) to the most clinically-significant antibiotics among clinical isolates of enterococci

\begin{tabular}{|c|c|c|c|c|c|c|c|}
\hline \multirow{3}{*}{ Antibiotic } & \multirow{3}{*}{$\begin{array}{l}\text { MIC Range } \\
(\mu \mathrm{g} / \mathrm{ml})\end{array}$} & \multicolumn{3}{|c|}{ E. faecalis $(\mathrm{n}=204)$} & \multicolumn{3}{|c|}{ E. faecium $(\mathrm{n}=87)$} \\
\hline & & \multicolumn{2}{|c|}{$\operatorname{MIC}^{\mathrm{a}}(\mu \mathrm{g} / \mathrm{ml})$} & \multirow{2}{*}{$\begin{array}{l}\text { HLR } \\
\text { No. (\%) }\end{array}$} & \multicolumn{2}{|c|}{ MIC $(\mu \mathrm{g} / \mathrm{ml})$} & \multirow{2}{*}{$\begin{array}{l}\text { HLR } \\
\text { No. (\%) }\end{array}$} \\
\hline & & $\mathrm{MIC}_{50}$ & $\mathrm{MIC}_{90}$ & & $\mathrm{MIC}_{50}$ & $\mathrm{MIC}_{90}$ & \\
\hline Ampicillin & $2-512$ & 16 & 64 & $45(22.06)$ & 32 & 128 & $39(44.83)$ \\
\hline Penicillin G & $2-512$ & 32 & 256 & $50(24.51)$ & 128 & 512 & $49(56.32)$ \\
\hline Gentamicin & $125-4000$ & 1000 & 2000 & $147(72.06)$ & 2000 & 4000 & $67(77.01)$ \\
\hline Streptomycin & $125-8000$ & 2000 & 4000 & $132(64.71)$ & 2000 & 8000 & $74(85.06)$ \\
\hline Vancomycin & $<0.5-2048$ & 4 & 64 & $27(13.24)$ & 4 & 256 & $18(20.69)$ \\
\hline Teicoplanin & $<0.5-256$ & 1 & 8 & $9(4.41)$ & 2 & 64 & $24(27.59)$ \\
\hline Linezolid & $<0.5-32$ & 1 & 1 & - & 1 & 1 & - \\
\hline
\end{tabular}

HLR, High-level resistance; MIC, minimum inhibitory concentration

${ }^{\mathrm{a}} \mathrm{MIC}_{50}$ and $\mathrm{MIC}_{90}$ : Minimum concentrations of antimicrobial that inhibits the growth of 50 and $90 \%$ of the isolates, respectively

limitedtherapeutic alternatives. If the infecting VRE is highly resistant to ampicillin and aminoglycosides, there are other suggested treatment options, including chloramphenicol, ciprofloxacin, erythromycin, linezolid, nitrofurantoin, rifampin, and tetracycline [1]. In this study, the magnitude of resistance was highest for ciprofloxacin $(95.5 \%)$, followed by erythromycin, tetracycline, nitrofurantoin, chloramphenicol, and rifampin. Linezolid had the lowest resistance rate of $2.4 \%$ (Table 1). Even though linezolid has demonstrated good anti-enterococcal activity, the emergence of linezolid resistance in enterococci is an alarming problem in the treatment of VRE infections [14]. Resistance to at least one agent of the three antimicrobial classes defining multidrug resistance was found in $57.0 \%(166 / 291)$ of all isolates [3]. Six isolates exhibited resistance to all tested antibiotics. This finding is of particular concern since the high prevalence of colonization and/or infection with MDR enterococci has reduced treatment options for these bacteria.

Another significant finding was the concomitant high-level resistance to the penicillins, aminoglycosides, and glycopeptides tested seen in $8.2 \%(24 / 291)$ of the isolates. Concomitant high-level resistance to these antibiotics has not been often reported in India $[12,15]$. Penicillins, aminoglycosides, and glycopeptides have been the mainstays of therapy for enterococcal infections; therefore, the organism's development to concomitant high-level resistance to these drugs would have important clinical implications, as it considerably narrows the therapeutic options.
In this study, E. faecium demonstrated a significantly higher frequency and extent of resistance as compared to $E$. faecalis for all tested antibiotics ( $P$ $<0.05$ ), which is consistent with the results of previous studies $[4,10,11,15]$.

This study illustrates the preferential spread of multidrug-resistant enterococci with highly raised MICs to most clinically significant antibiotics posing, thereby, a serious therapeutic challenge. This situation demands the implementation of an efficient infection control program and regular surveillance of antimicrobial resistance of enterococci in order to establish a rational antibiotic policy for the better management of enterococcal infections.

\section{References}

1. Cetinkaya Y, Falk P, Mayhall CG (2000) Vancomycinresistant enterococci. Clin Microbiol Rev 13: 686-707.

2. Murray BE (2000) Vancomycin-Resistant enterococcal infections. N Engl J Med 342: 710-721.

3. Magiorakos AP, Srinivasan A, Carey RB, Carmeli Y, Falagas ME, Giske CG, Harbarth S, Hindler JF, Kahlmeter G, OlssonLiljequist B, Paterson DL, Rice LB, Stelling J, Struelens MJ, Vatopoulos A, Weber JT, Monnet DL (2012) Multidrugresistant, extensively drug-resistant and pandrug-resistant bacteria: an international expert proposal for interim standard definitions for acquired resistance. Clin Microbiol Infect 18: 268-281.

4. Rahangdale VA, Agrawal G, Jalgaonkar SV (2008) Study of antimicrobial resistance in enterococci. Indian $\mathrm{J}$ Med Microbiol 26: 285-287.

5. Bhattacharya S (2011) Is screening patients for antibioticresistant bacteria justified in the Indian context? Indian J Med Microbiol 29: 213-217.

6. Manero A and Blanch AR (1999) Identification of enterococcus species with a biochemical key. Applied Environ Microbiol 65: 4425-4430. 
7. Dutka-Malen S, Evers S, Courvalin P (1995) Detection of glycopeptide resistance genotypes and identification to the species level of clinically relevant enterococci by PCR. J Clin Microbiol 33: 24-27.

8. Clinical and Laboratory Standards Institute (2009) Methods for Dilution Antimicrobial susceptibility tests for bacteria that grow aerobically; approved Standard- $8^{\text {th }}$ edition. CLSI document M7-A8 (ISBN 1-56238-689-1). Clinical and Laboratory Standards Institute, 940 West Valley Road, Suite 1400, Wayne, Pennsylvania 19087-1898 USA.

9. Clinical and Laboratory Standards Institute (2010) Performance standards for antimicrobial susceptibility testing: $20^{\text {th }}$ informational supplement. CLSI document M100-S20 [ISBN 1-56238-716-2]. Clinical Laboratory Standards Institute, 940 West Valley Road, Suite 1400, Wayne, Pennsylvania 19087-1898 USA.

10. Baragundi MC, Sonth SB, Solabannavar SS, Patil CS, Yemul VL (2010) Species prevalence and antimicrobial resistance pattern of enterococcal isolates in a tertiary health care centre. Journal of Clinical and Diagnostic Research 4: 3405-3409.

11. Adhikari L (2010) High-level Aminoglycoside Resistance and Reduced Susceptibility to Vancomycin in Nosocomial Enterococci. J Glob Infect Dis 2: 231-235.

12. Agarwal VA, Jain YI, Pathak A (1999) Concomitant highlevel resistance to penicillin and aminoglycosides in enterococci at Nagpur, Central India. Indian J Med Microbiol 17: 85-87.

13. European Centre for Disease Prevention and Control. Antimicrobial resistance surveillance in Europe (2009).
Annual Report of the European Antimicrobial Resistance Surveillance Network (EARS-Net). Stockholm: ECDC; 2010. Available: http://ecdc.europa.eu/en/publications/Publications/1011_SUR annual_EARS_Net_2009.pdf. Accessed 15 July 2011.

14. Sood S, Malhotra M, Das BK, Kapil A (2008) Enterococcal infections and antimicrobial resistance. Indian J Med Res 128: 111-121.

15. Mendiratta DK, Kaur H, Deotale V, Thamke DC, Narang R, Narang P (2008)Status of high-level aminoglycoside resistant Enterococcus faecium and Enterococcus faecalis in a rural hospital of Central India. Indian J Med Microbiol 26: 369371.

\section{Corresponding author}

Dr. Mohan G. Karmarkar

Department of Microbiology

Seth GS Medical College and KEM Hospital

Parel, Mumbai 400012

Maharashtra, India

Telephone: +91-22-24136051 Extn: 7985

Mobile: +919869284148

Email: rajivkarmarkar@yahoo.com; mohankarmarkar@kem.edu

Conflict of interests: No conflict of interests is declared. 